\title{
Anatomia do lenho de seis espécies de Ormosia (Leguminosae) da Amazônia
}

Arthur A. Loureiro (")

Pedro L. Braga Lisboa $\left({ }^{* *}\right)$

\begin{abstract}
Resumo
Neste trabalho, os autores apresentam o estudo dos caracteres anatômicos macro e microscópico de 6 espécies do gênero Ormosia (Leguminosae) - Ormosia coccinea, O. costulata, O. flava, O. macrocalyx 0. nobilis e $\mathbf{O}$. paraensis, todas da Amazônia, Para cad́a espécie são dadas as seguintes informacōes: caracteristicas gerais da madeira, descrição macruscúpica e microscópica, 6 macrofotografias e 12 microfotografias da estrutura das madeiras estudadas, 6 estampas esquemáticas das diferentes formas dos elementos vas. culares encontrados nas espécies, usos comuns e um quadro das principais caracteristicas anatômicas diferenciais das espécies estudadas.
\end{abstract}

\section{INTRODUÇÃo}

A denominação vulgar "Tento ou Mulungu" é atribuída com exatidão na Amazônia, às espécies do gênero Ormosia, com sementes geralmente bicolores (vermelho e preto), excelente para marcar jogo. Segundo Ducke (1949) é um gênero essencialmente tropical. Abrange cerca de 50 espécies lenhosas nos trópicos americanos e seu centro de dispersão no continente americano é a Amazônia.

A aplicação das madeiras do gênero já é uma realidade, mesmo considerando o seu pequeno uso na Amazônia brasileira. Algumas de suas espécies são usadas em construção civil e naval, cabos de ferramentas agrícolas, estacas, esteios e com grandes possibilidades para uso de tacos e dormentes, principalmente $O$. paraensis, $O$. coccinea e $O$. flava, por apresentarem uma boa resistência (cerne) ao ataque de fungos e cupins e com um aspecto muito atrativo de cor avermelhado, castanhoclaro e alaranjado, de superfície lisa e lustrosa recebendo excelente acabamento e também por serem as maiores do gênero atingindo cerca $\mathrm{de}_{\approx} 22$ a $28 \mathrm{~m}$ de altura, segundo nos- sas coletas realizadas no INPA - Manaus. Apesar da aplicabilidade comercial das madeiras do gênero Ormosia, alguns autores destacam o interesse econômico. Rudd (1965) relata que estas madeiras podem ser usadas para confecções de móveis, cabos de armas, dor. mentes de estrada de ferro, ripas e na construção em geral, apesar de Record \& Hess, (1949) afirmarem que são madeiras difíceis de trabaIhar, de acabamento pobre e durabilidade duvidosa. Realmente, algumas espécies do gênero estão dentro das afirmativas de Record \& Hess ( $/$ bid.), por apresentar árvores ou arvoretas de porte entre 6-8 $\mathrm{m}$ de altura e uma grã de regular para revessa. Geralmente essas essências têm o seu habitat próximos aos igarapés. Já expomos acima que muitas madeiras do gênero são excelentes para vários fins comerciais, talvez desconhecidas por Record \& Hess ( bid.)

Baseando-nos no pouco conhecimento que temos na Amazônia, sobre estas madeiras, propomos com o nosso trabalho contribuir para o conhecimento anatômico macro e micros. cópico de 6 espécies do gênero Ormosia da Amazônia, visando não somente o interesse econômico, mas, sobretudo, a auxiliar a taxonomia do gênero.

MATERIAL E MÉtodo

\section{MÉTODo}

O método empregado na obtenção das lâminas é aquele usado em xilologia.

\section{MATERIAL}

As preparações microscópicas do material Ienhoso autêntico para a descrição macroscópica e microscópica estão arquivadas nos

[ "] - Instituto Nacional de Pesquisas da Amazônia, Manaus.

(**) - Museu Paraense Emílio Goeldi, INPA - Belém. 
laminários do Instituto Nacional de Pesquisas da Amazônia, juntamente com o material de Herbário.

A terminologia usada para a descrição ana tômica é aquela aprovada pela Associação Bra. sileira de Normas Técnicas (1973).

\section{Ormosia coccinea Jacks.}

BRASIL - Estado do Amazonas: Municipio de Manaus, Estr. Manaus-Itacoatiara, Km 104. N.V. : Mulungu. Col.: L. Coelho, J. Lima \& Osmarino, s.n., em 08/05/68. Árvore de $28 \mathrm{~m} \times 38 \mathrm{~cm}$ de D.A.P. Circunferência do fuste na base $1,48 \mathrm{~cm}$; no meio 0,90 e no ápice $0,79 \mathrm{~cm}$; altura da copa $6,3 \mathrm{~m}$. Mata de terra firme. Herb. do INPA 21.223. $\mathrm{X}-$ 3.900; Estr. Manaus-Itacoatiara, $\mathrm{Km} 74$. Col. : W. Rodrigues \& auxiliares, $8535 \mathrm{em}$ $02 / 08 / 68$. Árvore de $27 \mathrm{~m} \times 33 \mathrm{~cm}$ de diâmetro. Mata de terra firme. Herb. do INPA $21.412, \mathrm{X}-3.980$.

\section{Ormosia costulata Ducke}

BRASIL - Estado do Amazonas : rio Cuieiras, sítio próximo ao igarapé do Tucunaré, pouco abaixo do repartimento. N.V.: Tento Col. : W. Rodrigues s.n., em 16/09/64. Det. : W. Rodrigues, em $12 / 1965$. Herb. do INPA 15,138 , $\mathrm{X}-2.989$.

\section{Ormosia flava (Ducke) Rudd}

BRASIL - Estado do Amazonas : Município de Manaus, Reserva Florestal Ducke, próximo a $\mathrm{Q}$. n. 34. Col. : A. Loureiro, L. Coelho \& F. Mello, s.n., em 09/04/64. Det. : A. A. Loureiro. Árvore de $25 \mathrm{~m} \times 70 \mathrm{~cm}$ de diâmetro. Terra firme argilosa. Herb. do INPA 14.450, $\mathrm{X}-2.627$.

\section{Ormosia macrocalyx Ducke}

BRASIL - Estado do Amazonas : margem do lago Inemazinho-Cambixe. N.V.: Sucupira. Col. : F. Mello, s.n., em 06/05/62. Árvore de 15m. Terreno argiloso. Herb. do INPA 12.726, $x-1.506$.

\section{Ormosia nobilis Tul.}

BRASIL - Estado do Amazonas: Município de Manăus, ig. da Cach. alta do Tarumã. N.V. : Molungu. Col.: W. Rodrigues \& J. Chagas, 2513 em 05/05/61. Árvore de $6 \mathrm{~m}$. Herb. do INPA 9.091, X - 942; Município de Manaus, ig. do Buião. N.V. : Molungu, Col. : J. Chagas, s.n., em $28 / 05 / 62$. Arvore de $5 \mathrm{~m}$. Herb. do INPA $12.959, \mathrm{X}-1.542$.

\section{Ormosia paraensis Ducke}

BRASIL - Estado do Amazonas: Município de Ma. naus, BR-17, $\mathrm{Km} 60 . \mathrm{N} . \mathrm{V}$. : Molungu da mata, Col.: W. Rodrigues \& Dionisio, 2225 em 15/03/61. Arvore de 22m. Herb do INPA 8.635, X - 879; Estr. AM-1, Km 155, picada XIX-63. N.V. : Tento. Col.: W. Rodrigues, s.n. Herb do INPA 17.402, X3.675; Estr. AM-1, Km 165, picada XXI-78. N.V.: Tento. Col.: W. Rodrigues, s.n. Herb. do INPA 17.403, X - 3.689; Estr. Manaus-Itacoatiara, $\mathrm{Km}$ 155, picada XIX. Col. : W. Rodrigues, 8999, em 11/12/71. Det. : W. Rodrigues, em 1971. Árvore de $22 \mathrm{~m} \times 20 \mathrm{~cm}$ de diâmetro. Herb. do INPA 28.469, X -4.176 .

\section{Ormosia coccinea Jacks.}

DADOS GERAIS SOBRE A MADEIRA

\section{C.ARACTERÍSTICAS GERAIS}

Madeira pesada $\left(0,80-0,90 \mathrm{~g} / \mathrm{cm}^{3}\right)$; cer. ne de cor avermelhada, às vezes com o decorrer do tempo apresenta algumas tonalidades alaranjadas, contrastando com o alburno creme com reflexos acinzentados; textura média para grosseira; grã revessa; gosto levemente amargo; cheiro indeterminado, superfície lus trosa. Boa de ser trabalhada.

DESCRIÇÃ̃o MACROSCÓPICA

(Foto 1)

Parênquima abundante, contrastado, perfeitamente visivel a olho nu, do tipo paratraqueal, em faixas concêntricas predominantes; a maioria larga, porém algumas vezes estreita; também parênquima aliforme confluente, formando trechos oblíquos ou não; eventualmente aliforme simples. Poros de muito pouco a porscos; bem visiveis a olho nu, médios; solitários predominantes, múltiplos de 2-3, raros; parcialmente obstruídos por substância alaranjada semelhante a goma. Linhas vasculares visiveis a olho nu, nas secçōes longitudinais. retas, contendo substância gomosa. Raios apenas visíveis à simples vista, apresentando 
uma uniformidade regular na largura e espa. çamento, poucos. Na secção tangencial, visi. veis só sob lente, irregularmente dispostos. $\mathrm{Na}$ secção radial, contrastados, visíveis a olho nu. Camadas de crescimento indefinidas, delimitadas por regiões fibrosas mais escuras. Máculas medulares ausentes.

\section{DESCRIÇÃO MICROSCÓPICA}

\section{(Fotos 2-3)}

Vasos de secção ovalada a circular, parede média, distribuição difusa, desuniforme, com algumas regiôes apresentando maior concentração, médios a grandes entre 120-240 $\mu \mathrm{m}$ de diâmetro tangencial, maioria de 140-210 $\mu \mathrm{m}$ $(80 \%)$, parciaimente obstruídos por substância semelhante à goma; de muito poucos a poucos, $0-5 \mathrm{p} / \mathrm{mm}^{2}$, com predominância de $2-3(36 \%)$; solitários predominantes $(76 \%)$ múltiplos de 2 $(20 \%)$ esporadicamente até $3-4$; placas de perfurações simples, inclinadas e retas, pontuaçōes intervasculares areoladas, guarnecidas, disposição alternas, inclusas; elementos vasculares de muito curtos a longos, com uma variação de $260-550 \mu \mathrm{m}$ de comprimento, mais freqüente entre $260-400 \mu \mathrm{m} \quad(92 \%)$, maioria com apêndices curtos e finos de um ou ambos os lados, conforme mostra o desenho esquemático (Fig. 1). Raios irregularmente dispostos, heterocelulares dos tipos II e III da clas. sificação de Kribbs; unisseriados mais comum $(74 \%)$, bisseriados $(26 \%)$, extremamente baixos, de $150-560 \mu \mathrm{m}$ de altura, maioria entre $400-500 \mu \mathrm{m}(39 \%)$; altura em número de células vai de 4-16, predominando os raios de 10-16 células $(69 \%)$; número de raios por $\mathrm{mm}$ linear 2-8, com maior freqüência de $4-6(72 \%)$. Presença de raios fusionados $(28 \%)$, variando de $360-720 \mu \mathrm{m}$, maioria entre $360-460 \mu \mathrm{m}(43 \%)$ : altura em número de células vai de $12-20$, predominando os raios de $13-16$ células $(42 \%)$; pontuações radiovasculares do mesmo tipo das intervasculares, um pouco menores. $\mathrm{Pa}$ rênquima axial do tipo paratraqueal em faixas largas, também aliforme simples de aletas largas e aliforme confluente. Cristais freqüentes nas células parenquimáticas, do tipo rom. boide, formando séries holocristalíferas, visiveis nos 3 cortes. Fibras de parede menor que o lúmen, variando $5-8 \mu \mathrm{m}$, em média $7-8 \mu \mathrm{m}$,

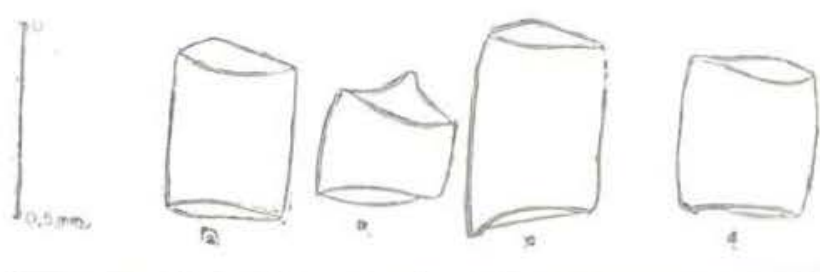

Fig. 1 - Ormosia coccinea Jacks. Desenho esquemático das diferentes formas dos elementos vasculares encontrados na espécie. (a, b, c, d).

elementos fibrosos de curtos a longos, 1.260. $1.860 \mu \mathrm{m}$ de comprimento, maioria entre 1.310 $1.600 \mu \mathrm{m}(72 \%)$. Camadas de crescimento não muito distintas, demarcadas pelo tecido fibroso, escuro e compacto.

\section{USOS COMUNS}

Construção civil e naval, cabo de ferramentas agrícolas, estacas, esteios, tacos e dormentes.

\section{Ormosia costulata (Miq.) Kleinh.}

\section{DADOS GERAIS SOBRE A MADEIRA}

\section{CARACTERÍSTICAS GERAIS}

Madeira pesada $\left(0,80-0,85 \mathrm{~g} / \mathrm{cm}^{3}\right)$; cerne castanho-escuro, levemente listrado, fibroso; alburno creme com tonalidades róseas às vezes entrelaçado de um cinza claro; textura pouco grosseira; grã revessa; sem cheiro $e$ gosto pronunciados; superficie de pouco lustre. Difícil de ser trabalhada com qualquer tipo de ferramenta.

\section{DESCRIÇÃO MACROSCÓPICA}

\section{(Foto 4)}

Parênquima axial abundante, muito contrastado, perfeitamente visivel a olho nu, do tipo paratraqueal, em faixas concêntricas la:gas, predominantes, onduladas, irregulares, às vezes interrompidas; algumas vezes aparecem mais espaçadas e outras vezes mais aproxima. das; também parênquima aliforme simples ou confluente, ambos ocasionais. Poros muito poucos a poucos, perfeitamente visiveis a olho nu, muito pequenos a grandes, solitários pre. 
dominantes, múltiplos de $2,3,4$, e 5; vazios ou ocasionalmente obstruídos por substância semelhante à goma. Linhas vasculares visiveis a olho nu nas secçōes longitudinais, leve. mente sinuosas. Raios apenas visiveis a olho nu, apresentando uma uniformidade regular na largura e espaçamento, poucos. Na secção tangencial visiveis só sob lente, irregularmen. te dispostos. Na secção radial, são contras. tados, visíveis a olho nu. Camadas de cresc: mento indefinidas. Máculas medulares ausen tes.

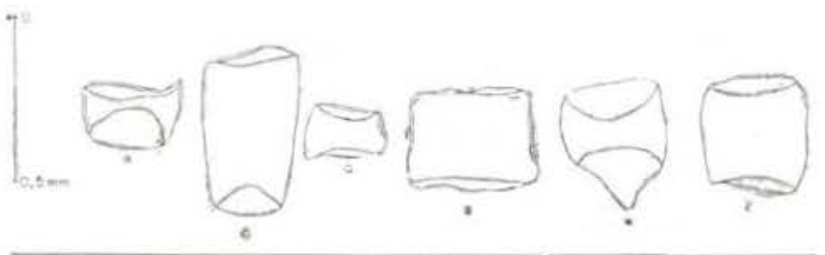

Fig. 2 - Ormosia costulata Ducke. Desenho esquema tico das diferentes formas dos elementos vasculares encontrados na espécie. (a, b, c, d, e, f).

DESCRIÇÃO MICROSCÓPICA

(Fotos 5-6)

Vasos de secção ovalada a circular, parede grossa, distribuição difusa, desuniforme, às vezes com regiōes apresentando maior concentração, de pequenos até grandes, entre 80-280 $\mu \mathrm{m}$ de diâmetro tangencial, maioria de $150-200 \mu \mathrm{m}$ ( $52 \%$ ); ocasionalmente obstruidos por substância semelhante à goma; de muito poucos a poucos numerosos, $1-8$ por $\mathrm{mm}^{2}$; solitários predominantes $(72 \%)$, múltiplos de $2-3$ $(28 \%)$; placas de perfuração simples; pontuaçôєs intervasculares areoladas, disposiçāo oposta, inclusas; elementos vasculares de muito curtos a curtos, com uma variação de $180-500 \mu \mathrm{m}$ de comprimento, mais freqüente entre $180-380 \mu \mathrm{m}(88 \%)$, alguns com apêndices curtos e finos em um ou em ambos os lados conforme mostra o desenho esquemático (Fig. 2). Raios irregularmente dispostos, heterocelulares, do tipo III da classificação de Kribbs; bisseriados predominantes $(68 \%)$, presente também unisseriados $(26 \%)$ e trisseriados $(6 \%)$, extremamente baixos, $110-360 \mu \mathrm{m}$ de altura, maioria entre $210-320 \mu \mathrm{m}(55 \%)$; altura em número de células vai de 5-15, predominando os raios de 11.15 células ( $53 \%$ ); núme- ro de raios por $\mathrm{mm}$ linear $3-10$, com maior fre. qüência de $7-8(56 \%)$. Presença de raios fusionados $(28 \%)$, variando de $260-730 \mu \mathrm{m}$, maioria entre $260-490 \mu \mathrm{m}(58 \%)$; altura em número de células vai de $10-25$, predominando os raios de $10-15$ células $(65 \%)$; pontuações radiovasculares do mesmo tipo das inter, um pouco menores. Parênquima axial do tipo paratraqueal em faixas irregulares, algumas vezes interrompidas, próximas, ocasionalmente aliforme simples ou confluente. Cristais presentes nas células do parênquima, vistos nas 3 secções, do tipo rombóide, formando séries holocristaliferas. Fibras de parede menor que o lúmen, variando de $3-8 \mu \mathrm{m}$, em média $6 \mu \mathrm{m}$; diâmetro do lúmen varia de 5 a 16 , em média $10 \mu \mathrm{m}$; pontuações simples; elementos fibrosos de extremamente curtos a longos, $450-1.650 \mu \mathrm{m}$, maioria entre 1.150-1.650 (84\%) de comprimento. Camadas de crescimento indistintas.

\section{USOS COMUNS}

Construção em geral, lenha e caibros.

\section{Ormosia flava (Ducke) Rudd}

DADOS GERAIS SOBRE A MADEIRA

\section{CARACTERISTICAS GERAIS}

Madeira pesada $\left(0,70-0,80 \mathrm{~g} / \mathrm{cm}^{3}\right)$; cerne castanho claro, pouco diferenciado do alburno de cor amarelado, passando com o tempo para amarelo queimado uniforme, às vezes entrelaçado de um cinza claro; textura grosseira; grã média; inodora; gosto levemente amargo; superficie pouco lustrosa. Um tanto facil de ser trabalhada, recebe bom acabamento.

DESCRIÇÃO MACROSCÓPICA

\section{(Foto 7)}

Parênquima axial abundante, muito contrastado, perfeitamente visível a olho nu, do tipo paratraqueal, aliforme confluente predominante, de aletas largas, irregulares, às vezes formando trechos oblíquos ligando vários poros também aliforme simples. Poros de muito pouco a pouco numerosos, perfeitamente vi- 
sivel a olho nu; pequenos a grandes; solitários predominantes, múltiplos de $2-3$, raríssimo de 4.5 poros; vazios ou freqüentemente obstruidos por substância semelhante à goma. Linhas vasculares bem visiveis a olho nu nas secções longitudinais, retas, às vezes conterdo substâncias da cor do lenho. Raios apenas visíveis a olho nu, apresentando uma uniformidade regular na largura e espaçamento. Na secção tangencial, visíveis somente sob lente, irregularmente dispostos. $\mathrm{Na}$ secção radial, bem contrastados, visíveis a olho nu. Camadas de crescimento indistintas. Máculas medula. res não foram observadas.

\section{DESCRIÇÃO MICROSCÓPICA}

(Fotos 8-9)

Vasos de secção ovalada a circular, pare. de média, distribuição difusa, desuniforme, pequenos a grandes, entre $60-290 \mu \mathrm{m}$ de diâmetro tangencial, maioria de $200-250 \mu \mathrm{m}(64 \%)$, vazios ou ocasionalmente obstruidos por substância semelhante à goma; de muito pouco a pouco numerosos, 2 a 6 por $\mathrm{mm}^{2}$, com predominância de 2-4; expecionalmente encontra-se de 1 e 7 vasos por $\mathrm{mm}^{2}$; solitários predominantes $(80 \%)$, placas de perfurações simples; pontuações intervasculares areoladas, guarnecidas, de disposição opostas, inclusas; elementos vasculares de muito curtos, com uma variaçäo de $200-490 \mu \mathrm{m}$ de comprimento, mais freqüente entre $350.460 \mu \mathrm{m}$, alguns com apêndice curtos e finos de um ou ambos os lados conforme mostra o desenho esquemático (Fig. 3). Raios irregularmente dispostos, homo e heterocelulares do tipo III da classificação de Kribbs, uni, bi e trisseriados, predominando os bisseriados $(66 \%)$, de extremamente baixos a muito baixos, de $110-930 \mu \mathrm{m}$ de altura, maioria entre $110.400 \mu \mathrm{m}(74 \%)$; altura em número de células vai de $5-49$, predominando os raios de $5-16$ células $(50 \%)$; número de raios por $\mathrm{mm}$ linear $3-6$, com maior freqüência de 5 raios $(36 \%)$. Presença de raios fusionados, $(24 \%)$, $610-1.000 \mu \mathrm{m}$ de altura, maioria entre $610-700$ $\mu \mathrm{m}(50 \%)$; altura em número de células vai de 29-40, predominando os raios de $38-40$ células $(43 \%)$; pontuações radiovasculares semelhantes às intervasculares. Parênquima axial do tipo paratraqueal, aliforme confluente predomi- nando, também aliforme simples de aletas largas tocando e envolvendo obliquamente vários poros. Cristais presentes nas células parenquimáticas do tipo rombóides, visiveis nas 3 secçōes, em séries holo e merocristaliferas. Fibras com parede maior que o lúmen, 6-10 $\mu \mathrm{m}$, em média $6 \mu \mathrm{m}$; diâmetro do lúmen varia de 5-8 $\mu \mathrm{m}$, em média $6 \mu \mathrm{m}$; elementos fibrosos de 1.530 a $2.400 \mu \mathrm{m}$, maioria entre $610-2.000 \mu \mathrm{m}$ $(76 \%)$ de comprimento. Camadas de crescimento indistintas.

\section{USOS COMUNS}

Dormentes, construção em geral, cabo de ferramentas, taboados, carpintaria.

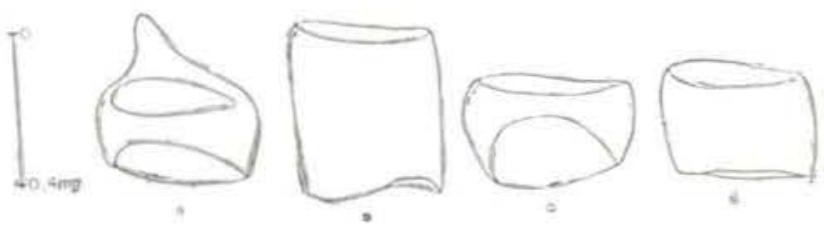

Fig. 3-Ormosia flava (Ducke) Rudd. Desenho esquemático das diferentes formas dos elementos vasculares encontrados na espécie. (a, b, c, d).

\section{Ormosia macrocalyx Ducke}

\section{DADOS GERAIS SOBRE A MADEIRA}

\section{CARACTERÍSTICAS GERAIS}

Madeira moderadamente pesada $(0,60-$ $0,75 \mathrm{~g} / \mathrm{cm}^{3}$ ); cerne castanho-escuro, levemente listrado, fibroso; alburno creme com tonali. dade rósea, às vezes entrelaçado de um cinzaclaro; textura pouco grosseira; grã revessa; sem cheiro e gosto pronunciados; superfície de pouco lustre. Difícil de ser trabalhada com qualquer tipo de ferramenta.

\section{DESCRIÇÃo MACROSCÓPICA}

$$
\text { (Foto 10) }
$$

Parênquima axial abundante, muito con. trastado, perfeitamente visivel a olho nu, do tipo paratraqueal em faixas obliquas ligando vá. rios poros, predominantes, também aliforme simples, de aletas curtas e grossas e aliforme confluente. Poros de muito pouco a pouco nu- 
merosos, perfeitamente visiveis a olho nu, pequenos a grandes; solitários predominantes. múltiplos de 2-3; vazios ou ocasionalmentt obstruídos por substância semelhante à goma. Linhas vasculares visiveis à simples vista nas faces longitudinais, não muito retas, contencu substância da cor do lenho. Raios visiveis sem auxilio de lente, apresentando uma uniformidade regular na largura e espaçamento. algumas vezes interrompidos. Na secção tangencial, visíveis só sob lente, irregularmente dispostos, baixos; na secçăo radial, são pou co contrastados, apenas visíveis a olho nu. $C a$ madas de crescimentc aparentemente demarcadas por zonas fibrosas mais escuras ou pe la pouca concentração de parênquima.

\section{DESCRIÇĀO MICROSCÓPICA}

(Fotos 11-12)

Vasos de secção ovalada a circular, parède grossa, distribuiçẫo difusa, desuniforme, com algumas regiöes onde associados ao parênquima axial se arrumam obliquamente; pequenos a grandes, entre $60-260 \mu \mathrm{m}$ de diâmetro tangencial, maioria de $140-220 \mu \mathrm{m}(64 \%)$; ocasionalmente obstruídos ora por tilos, ora por substância semelhante à goma; de muito poucos a pouco numerosos, 2-8 por $\mathrm{mm}^{2}$, com predominância de 3 a 5 ; solitários predominantes $(78 \%)$, múltiplos de $2(20 \%)$; placas de perfuraçōes simples; pontuaçōes intervasculares areoladas, de disposição opostas, inclusas; elementos vasculares muito curtos a curtos, com uma variação de $160-440 \mu \mathrm{m}$ de comprimento, mais freqüente entre $240-320 \mu \mathrm{m}$ $(52 \%)$, alguns com apêndices curtos e finos de um lado ou de ambos, conforme mostra o desenho esquemático (Fig. 4). Raios irregularmente dispostos, heterocelulares, do tipo III da classificação de Kribbs, multisseriados, predominando os raios de 3 células de largura $(50 \%)$, ocasionalmente unisseriados; extremamente baixos, de $100-470 \mu \mathrm{m}$, maioria entre $250-300 \mu \mathrm{m}(30 \%)$; número de raios por $\mathrm{mm} \mathrm{li}$ near $3-7$, ocasionalmente até 2 , com maior fre. quiência de 5-7 raios (64\%); havendo presença de raios fusionados $(24 \%)$ sua altura em número de células varia de 7-28 atingindo $530 \mu \mathrm{m}$ de altura; pontuaçōes radiovasculares do mesmo tipo das intervasculares. Parênquima axial

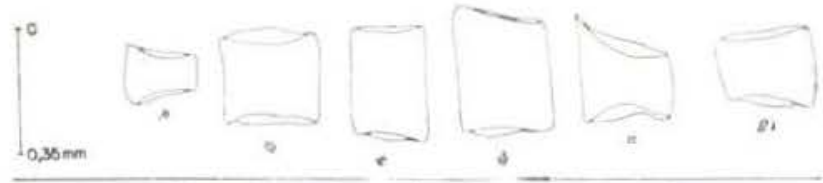

Fig. 4 - Ormosia macrocalyx Ducke. Desenho esquemático das diferentes formas dos elementos vasculares encontrados na espécie. (a, b, c, d, e, f).

do tipo paratraqueal predominando as faixas obliquas ligando vários poros; também aliforme simples de aletas curtas e grossas, às vezes se anastomosando. Cristais presentes nas células do parênquima axial e radial, do tipo rombóide, formando séries holocristalíeras e merocristalíferas. Fibras de parede menor que o lúmen, variando de $2.7-5 \mu \mathrm{m}$, em média $3 \mu \mathrm{m}$; diâmetro do lúmen varia de $5.4-13$ $\mu \mathrm{m}$, em média de $8 \mu \mathrm{m}$; elementos fibrosos de i. 200 a $1.730 \mu \mathrm{m}$, maioria entre $1.200-1.500$ $\mu \mathrm{m}(80 \%)$ de comprimento. Camadas de crescimento aparentemente demarcadas por pouca concentração do parênquima .

\section{USOS COMUNS}

Construções internas, carvão, lenha e caixas.

\section{Ormosia nobilis Tul.}

DADOS GERAIS SOBRE A MADEIRA

\section{CARACTERÍSTICAS GERAIS}

Madeira moderadamente pesada $(0,50-$ $\left.0,60 \mathrm{~g} / \mathrm{cm}^{3}\right)$; cerne róseo com tonalidade aver. melhadas, bem destacado do alburno de cor amarelado brilhante; textura média; grã regular, sem distinção de odor ou gosto; superficie brilhosa, recebe acabamento grosseiro, com polimento atrativo.

\section{DESCRIÇĀO MACROSCÓPICA}

(Foto 13)

Parênquima axial relativamente abundante, contrastado, perfeitamente visivel a olho nu. do tipo paratraqueal, aliforme simples predominante, de aletas losangulares, algumas vezes alongadas; também aliforme confluente, 
chegando a formar faixas concêntricas que em algumas regiões estão muito concentradas. Poros de pouco numerosos a numerosos, perfeitamente visíveis a olho nu, pequenos a mé. dios; solitários predominantes, múltiplos de 2-3 e raras cadeias radiais de até 5 poros vazios ou ocasionalmente obstruídos por substância semelhante à goma. Linhas vasculares visiveis a olho nu nas secções longitudinais, não muito retas, contendo substância da cor do lenho. Raios apenas visíveis a olho nu, finos; na secção tangencial, visiveis só sob lente, irregularmente dispostos, baixos. Na secção radial, são pouco contrastados, apenas perceptíveis à simples vista. Camadas de crescimento indistintas. Máculas medulares presentes, perfeitamente visiveis a olho desarmado.

\section{DESCRIÇÃO MICROSCÓPICA}

(Fotos 14-15)

Vasos de secção ovalada a circular, parede média distribuição difusa, desuniforme, com algumas regiōes apresentando maior concentraçāo de poros, pequenos a grandes, entre 80-250 $\mu \mathrm{m}$ de diâmetro tangencial, maioria de $120-200 \mu \mathrm{m}$ ( $68 \%)$, ocasionalmente obstruidos por substância semelhante à goma; de poucos a pouco numerosos, $5-8 \mathrm{p} / \mathrm{mm}^{2}$, com predominância de 5 a 6 , solitários predominantes $(78 \%)$, múltiplos de $2-3(27 \%)$ e raras cadeias radiais de até 5 poros; placas de perfuração simples; pontuaçōes intervasculares areoladas, de disposição oposta inclusa; elementos vasculares de muito curtos a curtos, com uma variação de 170-360 $\mu \mathrm{m}$ de comprimento, mais freqüente entre 230-260 $\mu \mathrm{m}$, alguns com apêndices curtos e finos de um ou ambos os lados, às vezes ausentes conforme mostra o desenho esquemático (Fig. 5). Raios irregularmente dispostos, dos tipos II e III da classificação de Kribbs; bisseriados mais comum ( $54 \%$ ), porém presentes unisseriados $(32 \%)$, extremamente baixos, de $140-390 \mu \mathrm{m}$ de altura, maioria entre 220-290 $\mu \mathrm{m}$ (53\%); altura em número de celulas vai de $4-15$ células, predominando os raios de $10-12$ células; número de raios por $\mathrm{mm} \mathrm{li-}$ near $4-8$, maioria $6-8$ raios $(76 \%)$. Presença de raios fusionados $(32 \%)$, variando de $250-790$ $\mu \mathrm{m}$, maioria entre $250-360 \mu \mathrm{m}(63 \%)$; altura em número de células vai de 9-30, predominando os raios de $13-16$ (58\%); pontuações radiovasculares do mesmo tipo das inter. Parênquima axial do tipo paratraqueal, aliforme simples predominante, também aliforme confluente, chegando a formar faixas. Cristais ausentes. Fibras de parede menor que o lúmen, de 2.7 $\mu \mathrm{m}$; diâmetro do lúmen varia de $8-13 \mu \mathrm{m}$, em média $11 \mu \mathrm{m}$; elementos fibrosos de muito curtos a longos, de $850-1.650 \mu \mathrm{m}$, maioria entre $1.350-1.650 \mu \mathrm{m}$ de comprimento. Máculas medulares presentes, freqüentes. Camadas de crescimento aparentemente demarcadas pelo tecido fibroso ou pela pouca concentração do parênquima.

\section{USOS COMUNS}

Caibros, ripados, lenha e carvăo.

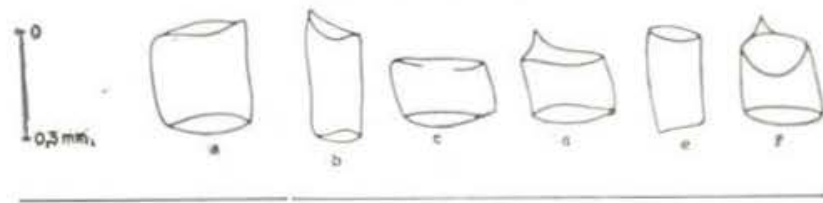

Fig. 5 - Ormosia nobilis Tul. Desenho esquemático das diferentes formas dos elementos vasculares encontrados na espécie. (a, b, c, d, e, f).

\section{Ormosia paraensis Ducke}

\section{DADOS GERAIS SOBRE A MADEIRA}

\section{CARACTERISTICAS GERAIS}

Madeira pesada $\left(0,75-0,80 \mathrm{~g} / \mathrm{cm}^{3}\right)$; cerne alaranjado pálido bem diferenciado do alburno de cor cinza com reflexos creme; textura grosseira; grã levemente irregular; gosto amargo, cheiro não pronunciado; superfície pouco lustrosa. Fácil de ser trabalhada.

\section{DESCRIÇÃO MACROSCÓPICA}

\section{(Foto 16)}

Parênquima axial abundante, muito contrastado, perfeitamente visível a olho nu, do tipo paratraqueal, aliforme confluente predominante, de aletas largas, chegando a formar tre. chos obliquos unindo vários poros, também aliforme simples. Freqüente em finas linhas con- 
cêntricas e intensificadas. Poros de poucos a pouco numerosos, perfeitamente visíveis a olho nu, pequenos a muito grandes; solitários predominantes, múltiplos de 2-3 raros de 4; vazios ou ocasionalmente obstruídos por substância semelhante à goma. Linhas vasculares visíveis a olho nu nas secções longitudinais, retas, às vezes contendo substâncias da cor do lenho. Raios visíveis a olho nu, apresentando uniformidade regular na largura e espaçamento. $\mathrm{Na}$ secção tangencial verceptíveis a olho nu, irregularmente dispostos, porém apresentando vários campos de estratifi. cação, esta de 3 a 4 por $\mathrm{mm}$. Na secção radial, pouco contrastados, visíveis a olho nu. Camadas de crescimento indistintas. Mácu. las medulares não foram observadas.

\section{DESCRIÇÃO MICROSCÓPICA}

\section{(Fotos 17-18)}

Vasos de secção ovalada a circular, parede média, distribuição difusa, mais ou menos uniforme, médios a muito grandes entre 170 $310 \mu \mathrm{m}$ de diâmetro tangencial, maioria de 190-280 $\mu \mathrm{m}$ ( $84 \%$ ), ocasionalmente obstruídos por substâncias semelhantes à goma, de muito poucos a pouco numerosos, 0-7 por $\mathrm{mm}^{2}$, com predominância de $0-3$; solitários predominantes $(77 \%)$, múltiplos de $2-3(23 \%)$, estes em disposição radial; placas de perfurações simples; pontuações intervasculares areoladas, disposição opostas, inclusas; elementos vasculares de muito curtos a curtos, com uma variação de $300-460 \mu \mathrm{m}$ de comprimento, mais freqüentes entre $300-350 \mu \mathrm{m}$, alguns com apêndices muito curtos de um ou ambos os lados conforme mostra o desenho esquemático (Fig. 6). Raios apresentando-se irregularmente dispostos em algumas regiões e, com campos de estratificações em outras, heterocelulares do tipo III da classificação de Kribbs; uni e trisseriados, predominando bisseriados $(66 \%)$, unisseriados $(20 \%)$ e trisseriados $(14 \%)$; na secção tangencial aparecem regiões nas quais as células radiais aparecem maiores e ladeadas por células parenquimáticas e elementos de vasos, somente; extremamente baixos de 210 $410 \mu \mathrm{m}$ de altura, maioria entre 210-330 $\mu \mathrm{m}$ $(74 \%)$; altura em número de células vai de 6-15, predominando os raios de 9-13 células

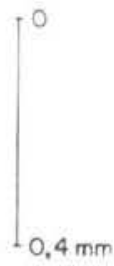

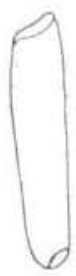

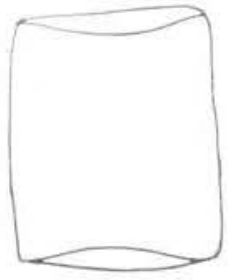

b

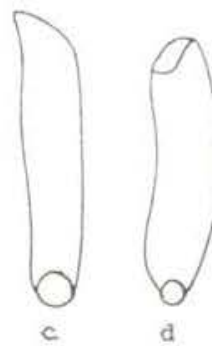

Fig. 6 - Ormosia paraensis Ducke. Desenho esquemá. tico das diferentes formas dos elementos vasculares encontrados na espécie. (a, b, c, d).

$173 \%)$; número de raios por $\mathrm{mm}$ linear $3-8$, com maior freqüência de $7-8(36 \%)$. Presença de raios fusionados, variando de $200-480 \mu \mathrm{m}$; altura em número de células vai de 9-16, predominando os raios de $13-16$ células $(43 \%)$; pontuações radiovasculares do mesmo tipo das intervasculares, um pouco menores. Parênquima axial do tipo aliforme confluente, predominante, às vezes formando faixas não muito largas, de 3-8 células de largura; aliforme simples, de aletas largas; também em linhas finas concêntricas e interrompidas. Cristais do tipo rombóide, presentes nas células do parênquima axial e radial, do tipo merocristalífero freqüente e raro holocristaliferos. Fibras de pontuações simples, areoladas, pequenas; espessura da parede $2.7-8 \mu \mathrm{m}$, em média 6.12 $\mu \mathrm{m}$; diâmetro do lúmen varia de 3-5 $\mu \mathrm{m}$, em média $4 \mu \mathrm{m}$; elementos fibrosos de curtos a longos, de 1.200 a $1.940 \mu \mathrm{m}$, mais comum entre 1.310 a $1.400 \mu \mathrm{m}$ de comprimento. Camadas de crescimento indistintas. Máculas medulares ausentes.

USOS COMUNS

Dormentes, carpintaria, tacos, esteios, construção civil e naval.

\section{REsultados}

As observações anatômicas estão contidas na descrição individual das madeiras, porém, com o objetivo de resumir os resultados elas foram reunidas na Tabela 1 onde é possível se estabelecer uma comparação mais ob. jetiva entre as espécies estudadas. 
TABELA 1 - Principais caracteres anatômicos diferenciais do lenho das espécies estudadas.

\begin{tabular}{|c|c|c|c|c|c|c|}
\hline e & $\begin{array}{l}\text { Ormosia } \\
\text { coccinea }\end{array}$ & $\begin{array}{l}\text { Ormosia } \\
\text { costulata }\end{array}$ & $\begin{array}{l}\text { Ormosia } \\
\text { flava }\end{array}$ & $\begin{array}{l}\text { Ormosia } \\
\text { macrocalyx }\end{array}$ & $\begin{array}{l}\text { Ormosia } \\
\text { nobilis }\end{array}$ & $\begin{array}{l}\text { Ormosia } \\
\text { paraensis }\end{array}$ \\
\hline $\begin{array}{l}\text { Peso } \\
\text { especifico }\end{array}$ & $0,80-0,90$ & $0,80-0,85$ & $0.70-0.80$ & $0,70-0,75$ & $0,50-0,60$ & $0,75-0,80$ \\
\hline $\begin{array}{l}\text { Cor (Cerne) } \\
\text { Cor (Alburno) }\end{array}$ & $\begin{array}{l}\text { avermelhada } \\
\text { cinza creme }\end{array}$ & $\begin{array}{l}\text { castanho escura } \\
\text { com listras } \\
\text { creme róseas }\end{array}$ & $\begin{array}{l}\text { castanho claros } \\
\text { amarelo escuras }\end{array}$ & $\begin{array}{l}\text { castanho escuras } \\
\text { creme róseas }\end{array}$ & $\begin{array}{l}\text { avermelhada } \\
\text { amarelada }\end{array}$ & $\begin{array}{l}\text { alaranjado pálida } \\
\text { cinza creme }\end{array}$ \\
\hline $\begin{array}{l}\text { Poros : } \\
\text { classificaçẫo }\end{array}$ & $\begin{array}{l}\text { solitários }(76 \%) \\
\text { múltiplos de } 2 \\
(20 \%)\end{array}$ & $\begin{array}{l}\text { solitários }(72 \%) \\
\text { múltiplos de } 2-3 \\
(28 \%)\end{array}$ & $\begin{array}{l}\text { solitários }(80 \%) \\
\text { múltiplos de } 2 \\
(20 \%)\end{array}$ & $\begin{array}{l}\text { solitários }(78 \%) \\
\text { múltiplos de } 2 \\
(20 \%)\end{array}$ & $\begin{array}{l}\text { solitários }(78 \%) \\
\text { múltiplos de } 2-3 \\
(22 \%)\end{array}$ & $\begin{array}{l}\text { solitário }(77 \%) \\
\text { múltiplos de } 2-3 \\
(23 \%)\end{array}$ \\
\hline $\begin{array}{l}\text { Raios : } \\
\text { tipos }\end{array}$ & $\begin{array}{l}\text { Heterocelular } \\
\text { Kribbs II e III }\end{array}$ & $\begin{array}{l}\text { Heterocelular } \\
\text { Kribbs III }\end{array}$ & $\begin{array}{l}\text { Homocelular e } \\
\text { Heterocelular } \\
\text { Kribbs III }\end{array}$ & $\begin{array}{l}\text { Heterocelular } \\
\text { Kribbs III }\end{array}$ & $\begin{array}{l}\text { Heterocelular } \\
\text { Kribbs II e III }\end{array}$ & $\begin{array}{l}\text { Heterocelular } \\
\text { Kribbs III }\end{array}$ \\
\hline $\begin{array}{l}\text { Largura dos } \\
\text { ráios em } \mathrm{N}: \\
\text { de células }\end{array}$ & $\begin{array}{ll}\text { unisseriado } & 74 \% \\
\text { bisseriado } & 26 \%\end{array}$ & $\begin{array}{lr}\text { unisseriado } & 26 \% \\
\text { bisseriado } & 68 \% \\
\text { trisseriado } & 6 \%\end{array}$ & $\begin{array}{ll}\text { bisseriado } & 66 \% \\
\text { trisseriado } & 34 \%\end{array}$ & \begin{tabular}{|lr} 
unisseriado & $6 \%$ \\
bisseriado & $20 \%$ \\
trisseriado & $50 \%$ \\
tetrasseriado & $24 \%$
\end{tabular} & $\begin{array}{ll}\text { unisseriado } & 32 \% \\
\text { bisseriado } & 54 \% \\
\text { trisseriado } & 14 \%\end{array}$ & $\begin{array}{|ll|}\text { unisseriado } & 20 \% \\
\text { bisseriado } & 66 \% \\
\text { trisseriado } & 14 \%\end{array}$ \\
\hline $\begin{array}{l}\text { Ráios por } \\
\mathrm{mm} \text { linear }\end{array}$ & $\begin{array}{l}\text { de } 2-8 \text {, maioria } \\
4-6(72 \%)\end{array}$ & $\begin{array}{l}\text { de } 3-10 \text {, maioria } \\
\text { entre } 7-8(56 \%)\end{array}$ & $\begin{array}{l}\text { de } 3-6 \text {, maioria } \\
\text { de } 5(36 \%)\end{array}$ & $\begin{array}{l}\text { de } 3-7 \text {, maioria } \\
\text { entre } 5-7(64 \%)\end{array}$ & $\begin{array}{l}\text { de } 4-8, \text { maioria } \\
6-8(76 \%)\end{array}$ & $\begin{array}{l}\text { de } 3-8, \text { maioria } \\
7-8(36 \%)\end{array}$ \\
\hline $\begin{array}{l}\text { Parênquima } \\
\text { axial : } \\
\text { tipo }\end{array}$ & $\begin{array}{l}\text { Paratraqueal em faixas } \\
\text { largas, também alifor- } \\
\text { me simples de aletas } \\
\text { largas e aliforme con- } \\
\text { fluente. }\end{array}$ & $\begin{array}{l}\text { Paratraqueal em faixas } \\
\text { irregulares, algumas ve } \\
\text { zes interrompidas, pró- } \\
\text { ximas, ocasionalmente } \\
\text { aliforme simples e con- } \\
\text { fluente. }\end{array}$ & $\begin{array}{l}\text { Paratraqueal, aliforme } \\
\text { confluente predominan- } \\
\text { do, também aliforme } \\
\text { simples de aletas lar- } \\
\text { gas tocando e envol- } \\
\text { vendo obliquamente vá- } \\
\text { rios poros. }\end{array}$ & $\begin{array}{l}\text { Paratraqueal. predomi } \\
\text { nando as faixas obli- } \\
\text { quas ligando vários po } \\
\text { ros; também aliforme } \\
\text { simples de aletas cur- } \\
\text { tas e grossas. }\end{array}$ & $\begin{array}{l}\text { Paratraqueal, aliforme } \\
\text { simples predominante, } \\
\text { também aliforme con- } \\
\text { fluente, chegando a } \\
\text { formar faixas. }\end{array}$ & $\begin{array}{l}\text { Paratraqueal, aliforme } \\
\text { confluente, predomi- } \\
\text { nante, às vezes for- } \\
\text { mando faixas não mui- } \\
\text { to largas, de } 3-8 \text { célu- } \\
\text { las de largura; alifor } \\
\text { me simples, de aletas } \\
\text { largas; em linhas fi- } \\
\text { nas concêntricas e in- } \\
\text { terrompidas. }\end{array}$ \\
\hline
\end{tabular}




\section{DISCUSSÃO E CONCLUSÕ̃S}

As madeiras submetidas a estudo anatômico mostram uma semelhança marcante entre si, o que não chega a surpreender considerando que sob o aspecto anatômico do lenho, as madeiras caracterizam-se mais a nível genérico do que a nível de família ou outro taxon qualquer.

Apesar da íntima relação, é possível, entretanto, diferençá-las macroscopicamente com lupa de $10 \mathrm{X}$ de aumento.

Abaixo, é analisado cada elemento de identificação considerado importante anatomica. mente para tal fim.

Poros - A presença mais freqüente de poros em cadeias em Ormosia coccinea, $\mathbf{O}$. flava e $\mathbf{O}$. macrocalyx permite separá-las das outras espécies cuja predominância é sobretudo de poros solitários e múltiplos de 2 .

Raios - A ocorrência de raios com tipos de Kribbs II e III (Ormosia coccinea e O. nobilis) e Kribbs III (Ormosia costulata, O. flava e O. macrocalyx) fornece outro subsidio relevan. te para separar as espécies e, no caso particular de $\mathbf{0}$. flava a presença de raios homocelulares facilita a separação definitive.

Parênquima - Mesmo havendo semelhança entre os parênquima, é possível separar as seis espécies em dois grupos. Um grupo com parênquima evidentemente abundante $\mathbf{C}$. coccinea, O. costulata e O. macrocalyx), predominando as faixas. Em O. macrocalyx as faixas se dispõem de modo oblíquo caracterizando particularmente esta espécie. O outro grupo (O. flava, O. nobilis e $\mathbf{O}$. paraensis), constituído de parênquima menos abundante e com predominância de aliforme simples e confluente.

Os outros caracteres contidos na Tabela 1 são suplementares de pouca utilidade para a separação dos taxon.

\section{ATLAS DAS MACRO E MICROFOTOGRAFIAS DAS SECCOOES TRANSVERSAL E TANGENCIAL DAS ESPÉCIES ESTUDADAS}

As macrofotografias com $10 \mathrm{X}$, foram obtidas diretamente das superfícies de topo dos corpos de prova, preparados convenientemente em micrótomo Jung. R. Jungag, fotografa dos com microscópio estereoscópio Olympus SZ.

As microfotografias com $50 \mathrm{X}$, foram adquiridas diretamente das lâminas histológicas com microscópio Olympus Trinocular FH, cảmara Olympus.

As fotos são dispostas segundo a ordem alfabética das espécies.

\section{SUMMARY}

This paper presents the macroscopical and microscopical descriptions of the structure of wood of the following amazonian species of Leguminosae: Ormosia coccinea, Ormosia costulata, Ormosia flava, Ormosia macrocalyx, Ormosia nobilis and Ormosia paraensis. 18 illustrations of the woods described, 6 esquematic prints of different shapes of vascular elements encountered in the species studied, common uses and a list of principals anatomical characteristics are included in this paper.

\section{AGRADECIMENTOS}

Somos gratos a todos quanto, direta ou indiretamente, nos ajudaram colaborando para a execução deste trabalho. Todavia, devido a uma contribuição mais direta somos especial. mente gratos :

Aos auxiliares técnicos: Wilson Meirelles, Darlinda Bastos, extensivos também aos coletores: Osmarino Monteiro, Luiz Coelho, J. Chagas, Dionísio Coelho, Francisco Mello e João Lima.

Aos Engenheiros de Operação na Modalidade de Indústria da Madeira: Lúcia Tinôco, José Francisco Lemos e Edmara Seffair, pela colaboração na contagem de alguns elementos constituintes do lenho; aos desenhistas Jorge Palheta e Alberto Silva, nossa gratidão.

\section{BIBLIOGRAFIA}

Associação Brasileira de Normas técnicas

1973 - Descrição dos caracteres gerais e anatômicos macro e microscópicos das madeiras de dicotiledôneas brasileira. Rio de Janeiro, p. 18 (mimeografado).

DUCKE, A.

1949 - Notas sobre a Flora Neotrópica - II. As Leguminosas da Amazônia Brasileira. 2. ed. Bol. Téc. IAN, 18: 105-108.

RUDD, V, E.

1965 - The American species of Ormosia (Leguminosae). Bull. United States National Museum, 32 (5): $391 \mathrm{p}$.

(Aceito para publicação em 01/10/79) 
Ormosia coccinea Jacks.

Foto 1

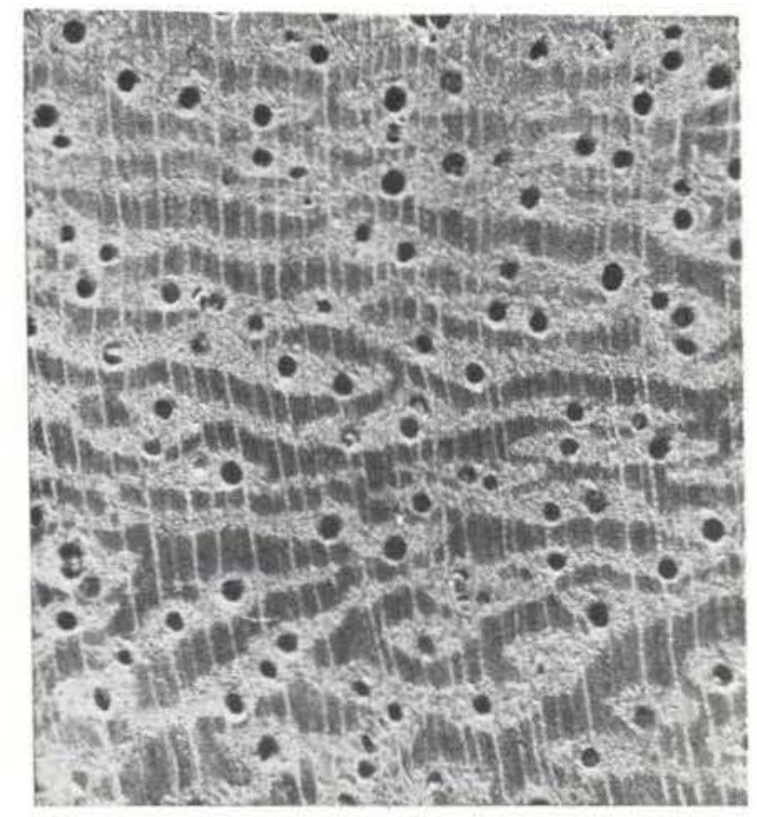

Secçāo transversal (10X)

Foto 2

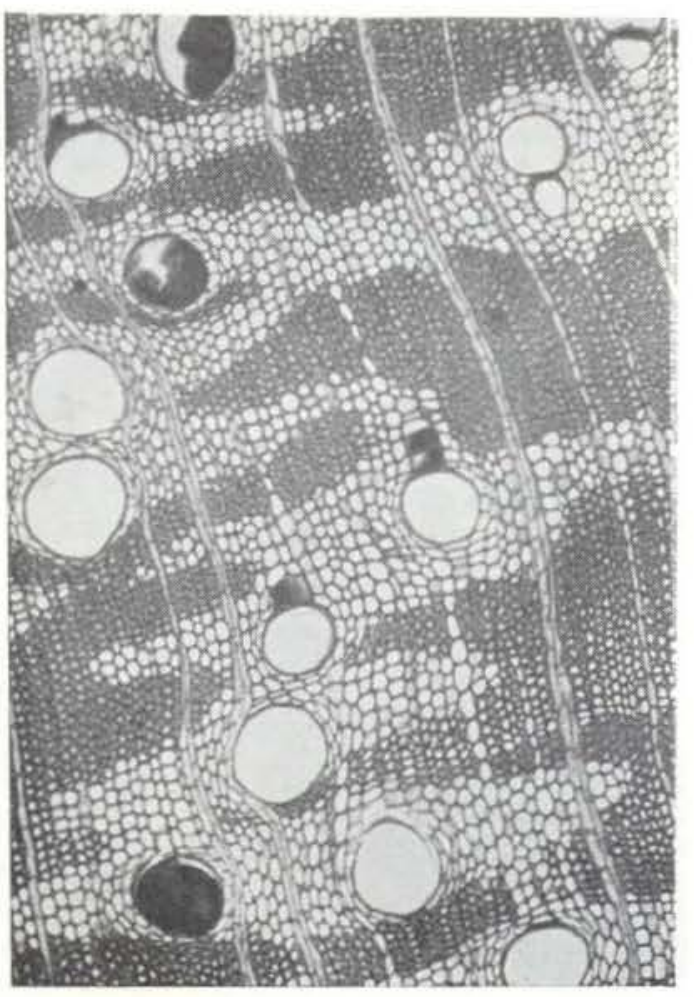

Secção transversal (50X)
Foto 3

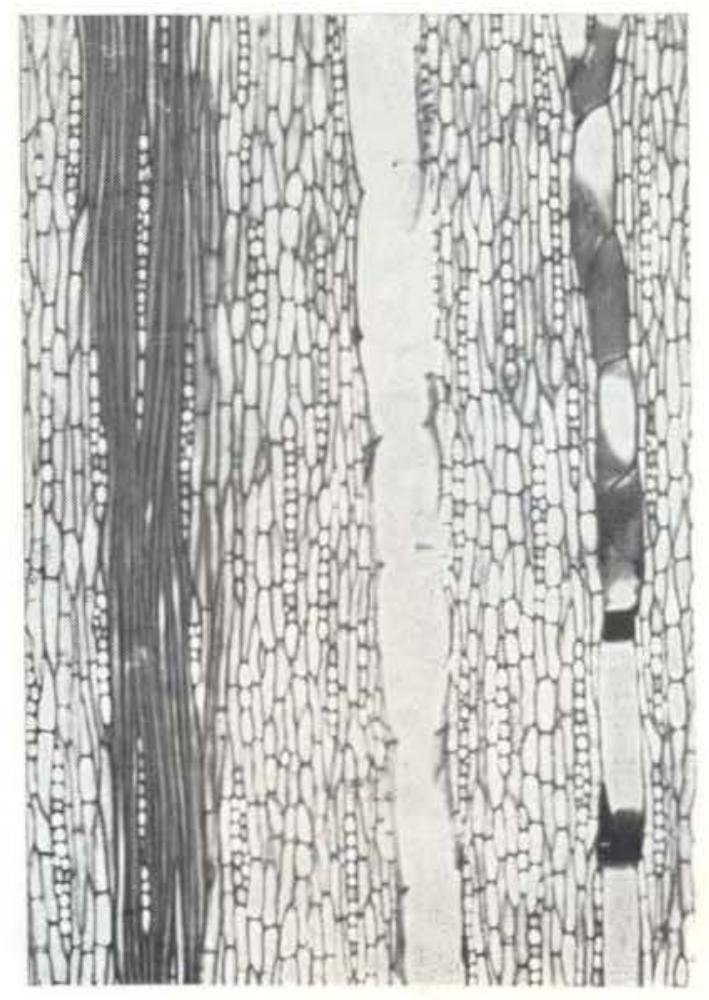

Secçāo tangencial (50X) 
Ormosia costulata Ducke

Foto 4

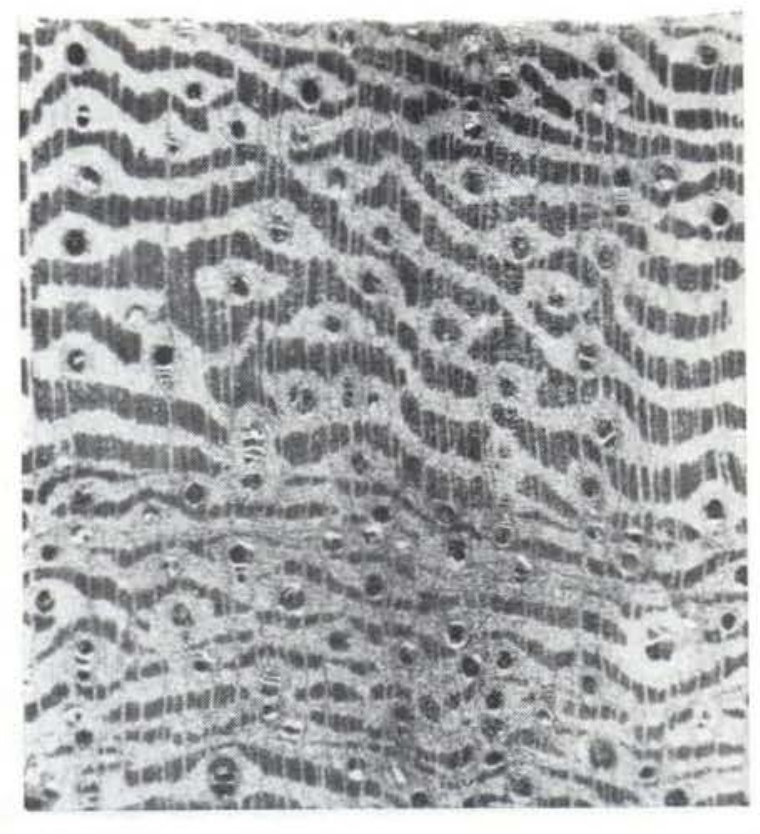

Secção transversal [10X]

Foto 5

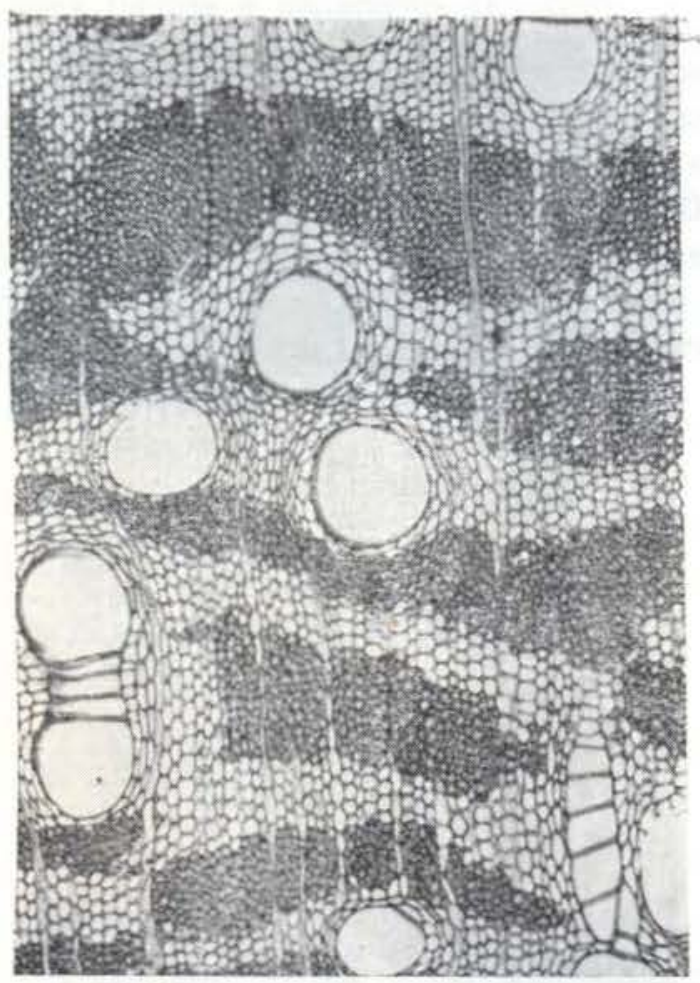

Secção transversal (50X)
Foto 6

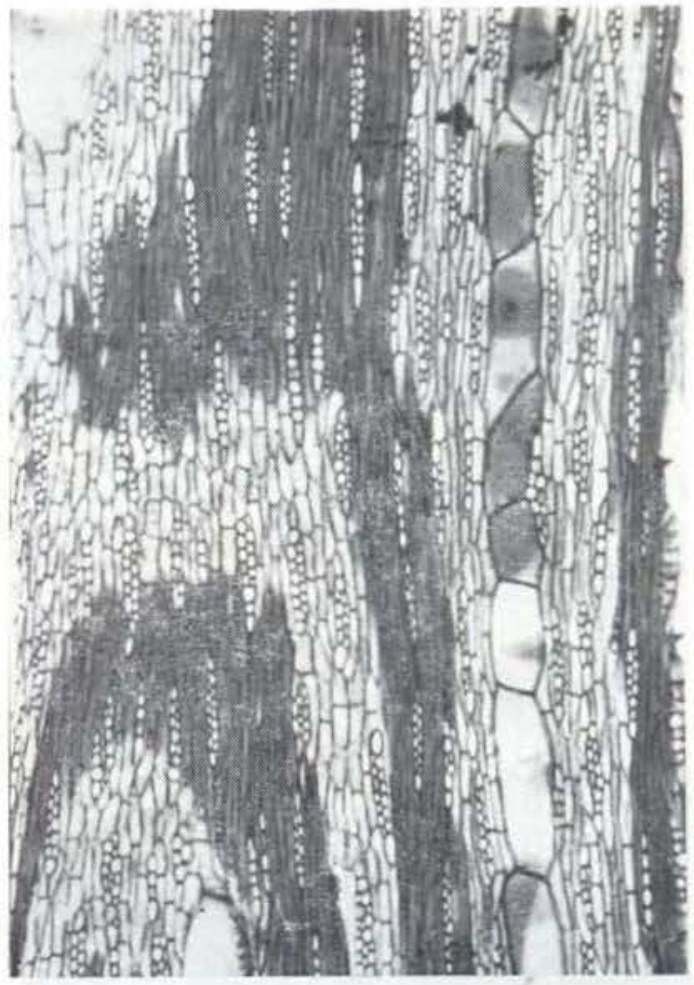

Secção tangencial (50X) 
Ormosia flava (Ducke) Rudd.

Foto 7

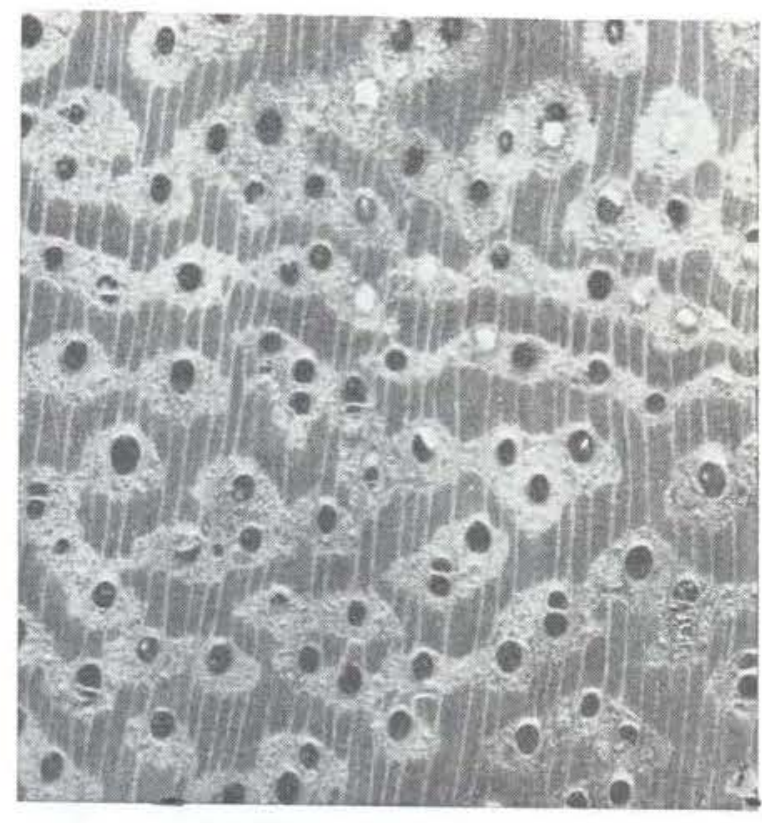

Secção transversal (10X)

Foto 8

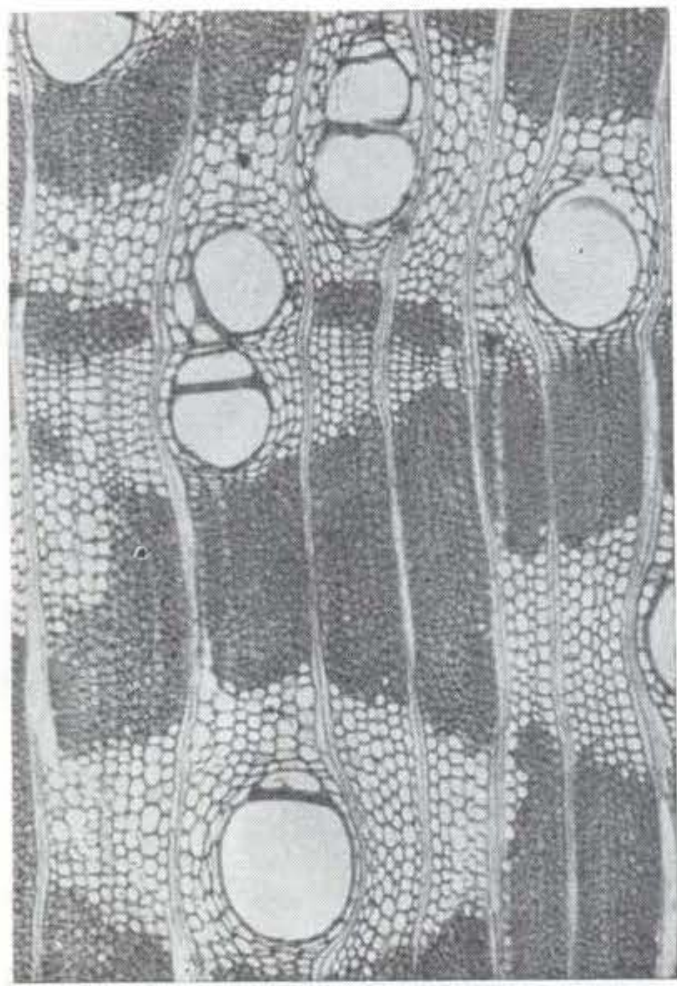

Secção transversal (50X)
Foto 9

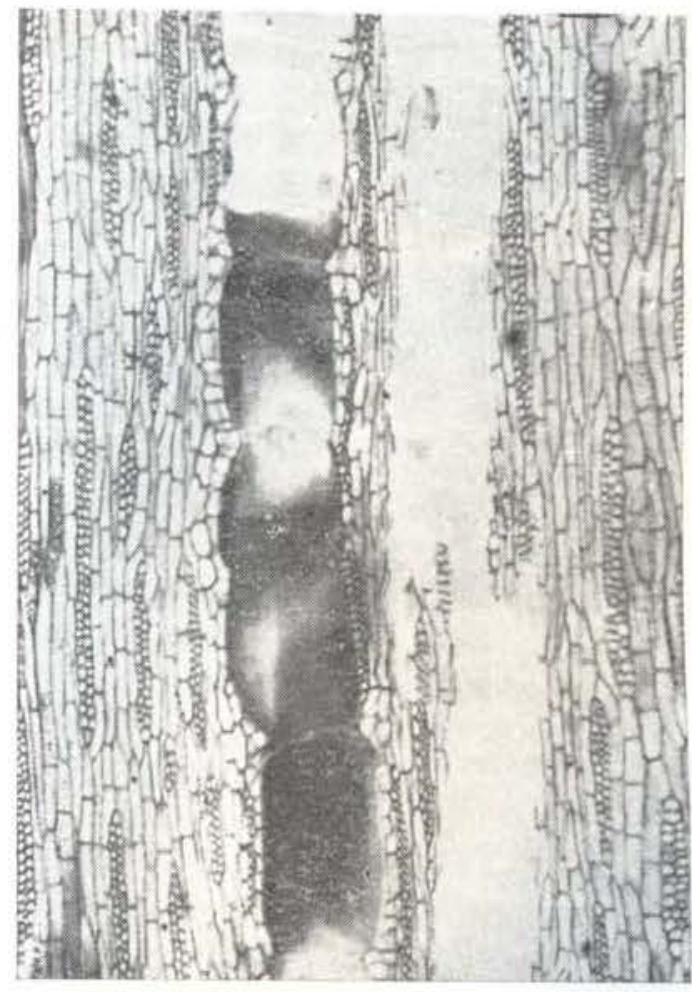

Secção tangencial (50X) 
Ormosia macrocalyx Ducke

Foto 10

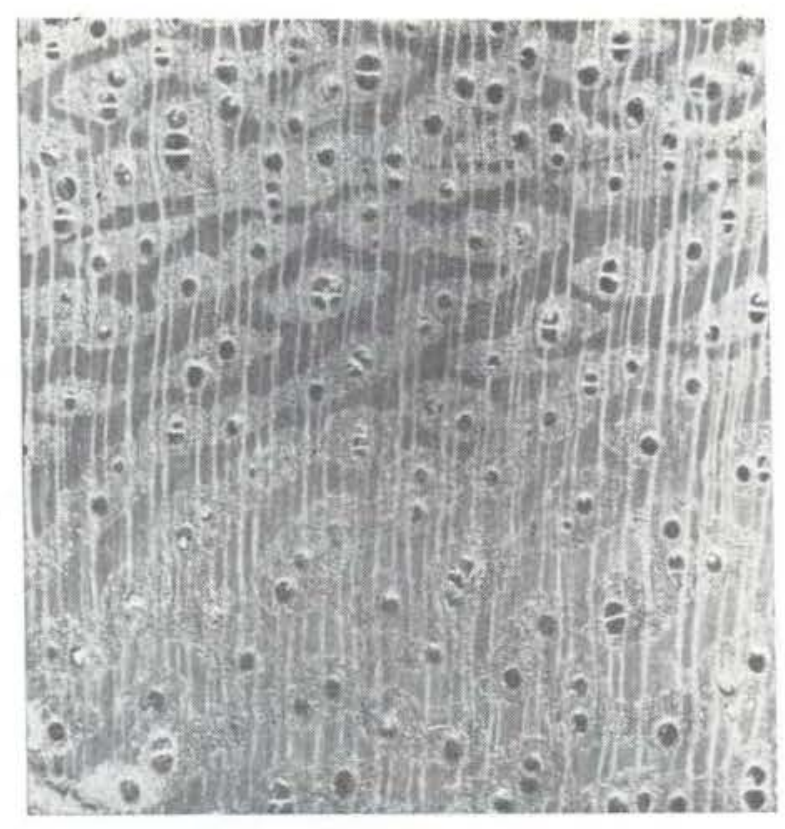

Secçåo transversal (10X)

Foto 11

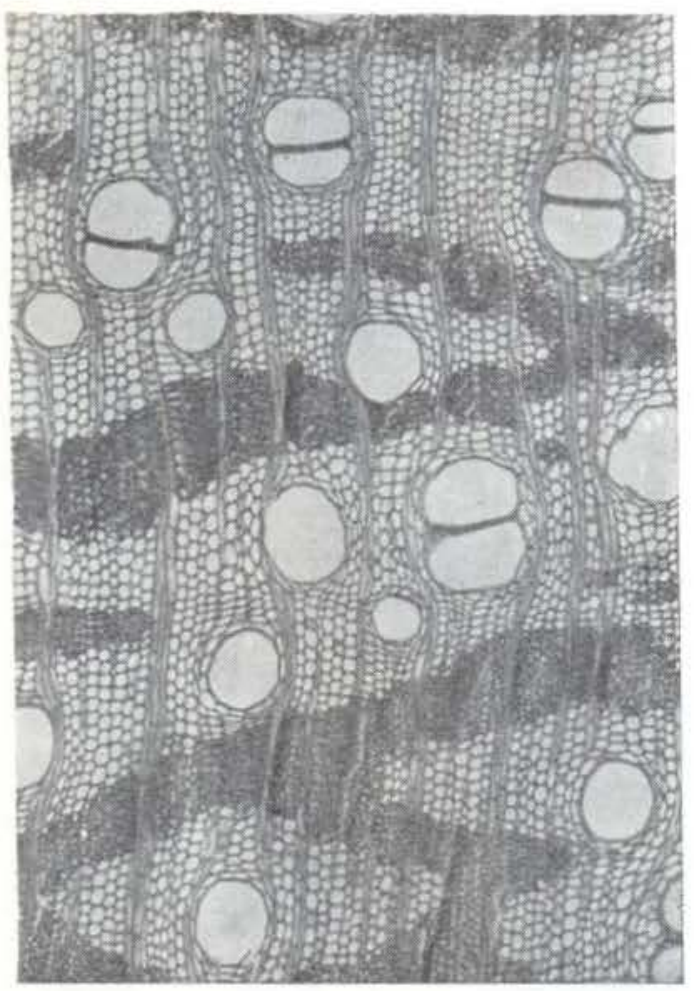

Secção transversal (50X)
Foto 12

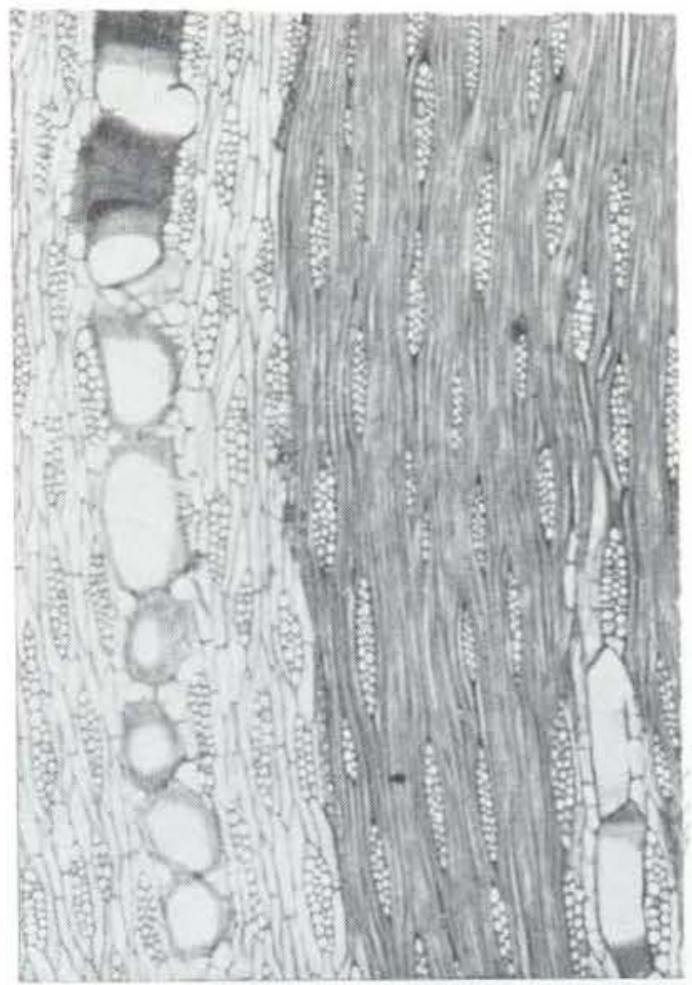

Secçăo tangencial (50X)

Loureiro \& Lisboa 
Ormosia nobilis Tul.

Foto 13

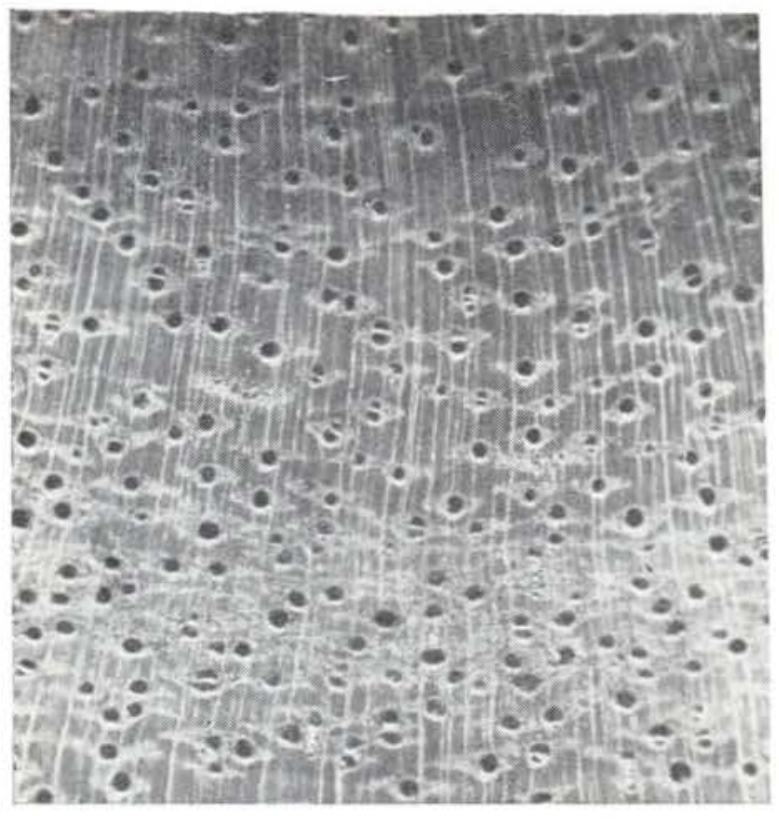

Secçẩo transversal (10X)

Foto 14

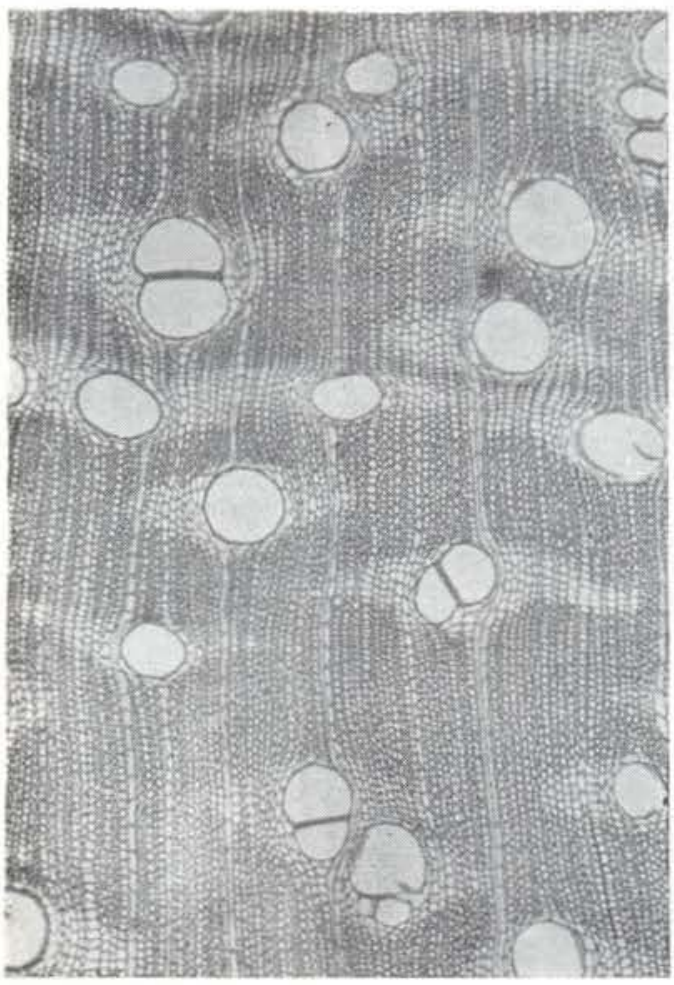

Secçẫo transversal (50X)
Foto 15

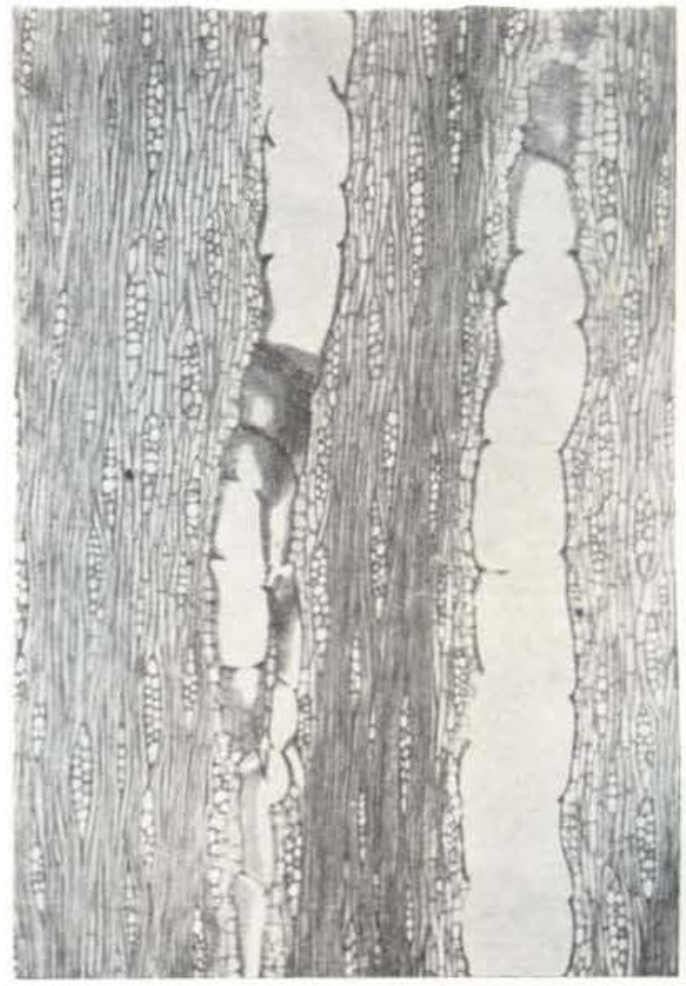

Secçâo tangencial (50X)

Anatomia do... 
Ormosia paraensis Ducke

Foto 16

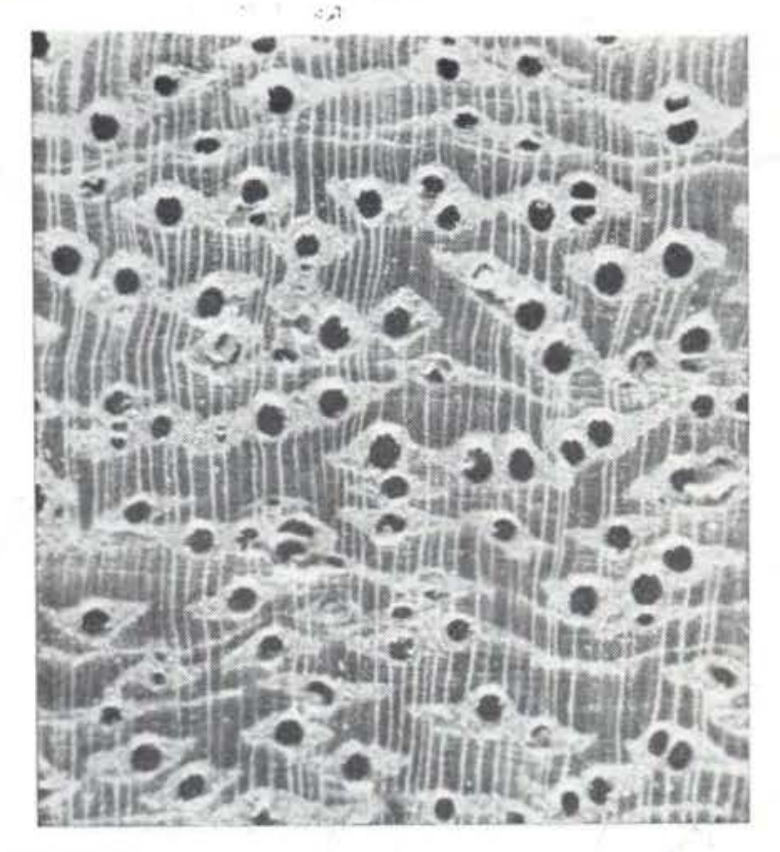

Secçäo transversal (10X)

Foto 17

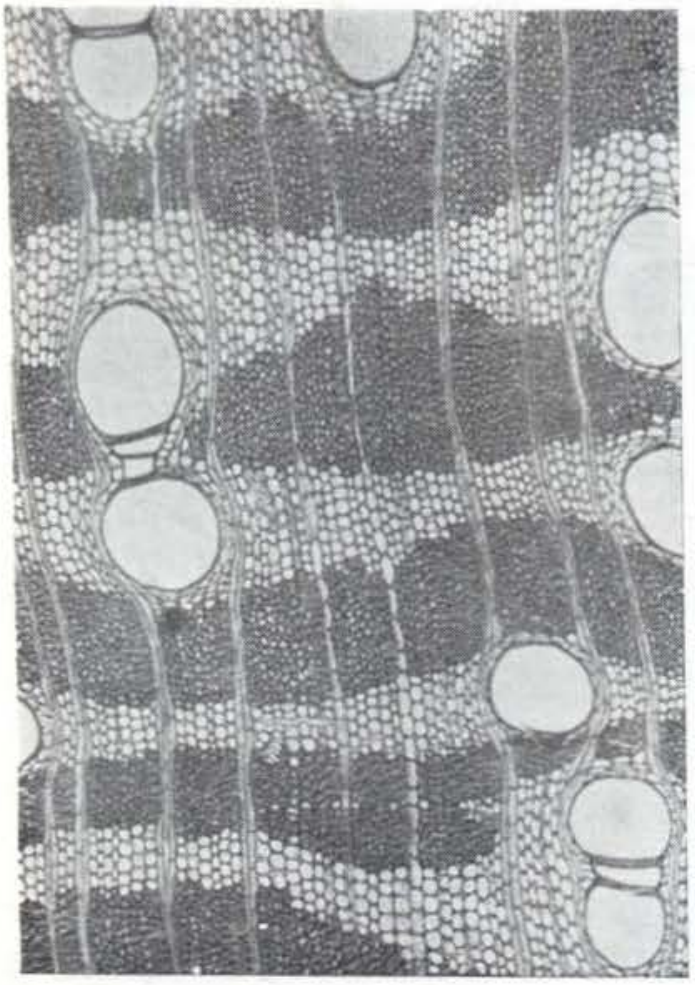

Secçāo transversal (50X)
Foto 18

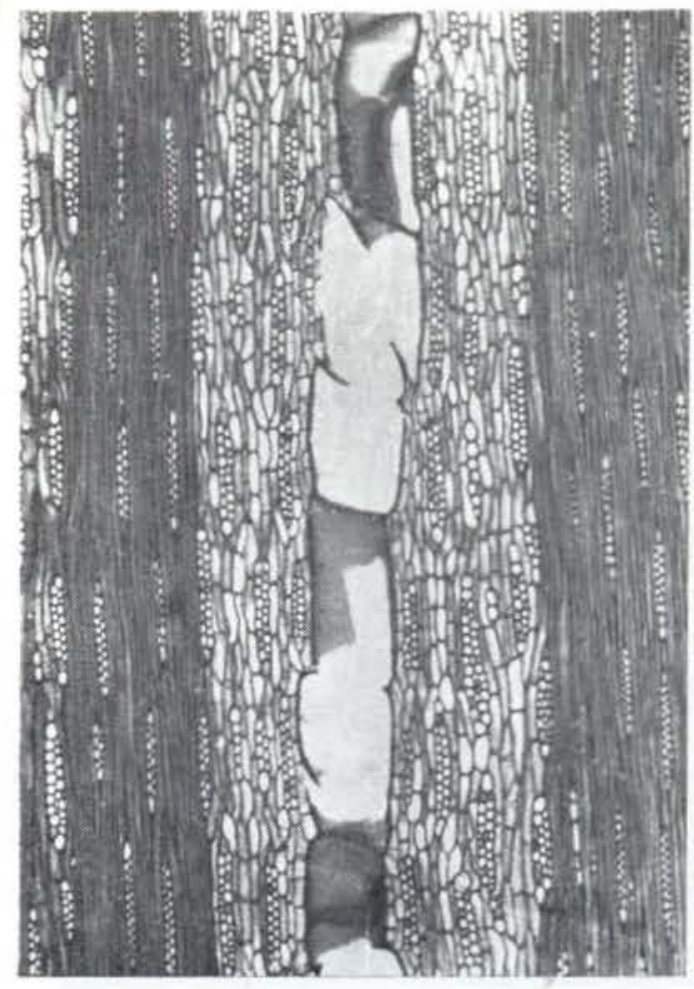

Secção tangencial ( $50 \mathrm{X}$ ) 